\title{
Phenotypic and molecular characterization of multidrug-resistant extended- spectrum beta-lactamase-producing Salmonella prevalent in raw chicken meat vended in Nigerian markets
}

\author{
Gideon Ikechechukwu OGU, ${ }^{1,2}$ Faith Iguodala AKINNIBOSUN,${ }^{3}$ and Odaro Stanley IMADE ${ }^{* 4}$
}

\author{
${ }^{1}$ Department of Biological Sciences, Novena University, P.M.B 002, Ogume, Delta State, Nigeria \\ ${ }^{2}$ Department of Microbiology, Faculty of Science, Federal University Lokoja, Kogi State, Nigeria \\ ${ }^{3}$ Department of Microbiology, Faculty of Life Sciences, University of Benin, P.M.B 1154, Benin City, Edo State, Nigeria \\ ${ }^{4}$ Department of Biological Sciences, College of Natural \& Applied Sciences, Igbinedion University, Okada, Edo State, \\ Nigeria
}

\begin{abstract}
In Nigeria, there is still a scarcity of data on the recovery of multidrug-resistant ESBL-producing Salmonella in chicken meat. Hence this study characterized the probable multidrug-resistant extended-spectrum beta-lactamaseproducing Salmonella prevalent in chilled raw chicken meat vended in Nigerian markets. Detection of Salmonella was performed by meat rinse centrifugation-plating technique. Presumptive Salmonella colonies were identified by phenotypic and 16S rRNA gene sequencing. The confirmed Salmonella isolates were tested for multidrug resistance by the Kirby Bauer disc diffusion test. Detection and confirmation of extended-spectrum beta-lactamase (ESBL) phenotypes were performed by double disc synergy and combination disc tests. PCR and DNA sequencing of the ESBL-encoding genes $\left(b_{1} a_{\mathrm{SHV}}, b_{1} a_{\mathrm{TEM}}\right.$, and bla $\left._{\mathrm{CTX}-\mathrm{M}}\right)$ were also performed. The conserved and three-dimensional (3D) domains in ESBLs were respectively characterized by the reverse position-specific BLAST (RPS-BLAST) and Cn3D modeling tool. Of the 229 presumptive Salmonella isolates examined, 52 isolates were confirmed as Salmonella species, 46 isolates were multidrug-resistant and 41 isolates confirmed as multidrug-resistant ESBL-producing Salmonella species. The main serotypes were Salmonella enterica subsp. enterica serovar Typhimurium (35/52; 67.31\%) and Salmonella enterica subsp. enterica serovar Enteritidis (17/52;32.69\%). Overall, the prevalence of chilled raw chicken meat contaminated with Salmonella was estimated at $0.17(40 / 240)$. This value of prevalence exceeded the limits $(\leq 0.1)$ set by the Meat Industry Guide, United Kingdom. All CTX-M, TEM, and SHV beta-lactamases produced by the Salmonella isolates were confirmed by RPS-BLAST and Cn3D modeling tool as serine-based hydrolases that consisted of two 3D domains with unique ligands such as sodium ion, formic acid, and glycerol. This study showed that multidrug-resistant ESBL-producing Salmonella was widespread in raw chicken meat vended in Nigerian markets. Thus, there is a need for relevant regulatory agencies to enforce safety.
\end{abstract}

Keywords: Salmonella; multidrug-resistant; extended-spectrum beta-lactamase; RPS-BLAST; Cn3D modeling tool.

\section{Introduction}

Million cases still occur annually from salmonellosis in both humans and animals [1]. Salmonellosis has been variously linked to poultry products resulting in economic losses, as well as animal and human losses [2]. Foodborne infections have been underreported worldwide, especially, in developing countries where there are inadequate health facilities and personnel that are needed to carry out scientific investigations [3]. The open markets and other premises in the developing countries where chicken meat is vended are often not monitored by the relevant regulatory authorities, thereby creating a high probability of improper sanitary practices amongst the retailers and other meat handlers. This lack of regulatory surveillance might have contributed to a high prevalence of isolation of Salmonella chicken meat from the developing countries $[4,5]$. The risk factors that have contributed to the high frequency of Salmonella in chicken meat from the developing countries include storage temperature, rearing conditions, and the sources of chicken $[4,6,7]$. The prevalence of Salmonella in chicken meat from the developing countries ranged from $11 \%$ to $65 \%[8,9]$. Irrespective of the stringent measures implemented in the developed countries to control salmonellosis on poultry farms and retailing outlets, Salmonella has been reported at a prevalence that ranged from 4 to $20 \%$ [10, 11]. TEM (Temoneira), SHV (sulfhydryl variable active sites) and CTX-M (cefotaximase hydrolyzing activity) beta-lactamases have been variously reported in Salmonella species [12-15]. Currently, many countries have witnessed a rise in the CTX-M variants [16, 17]. Several researchers have stated that extended-spectrum beta-lactamase-producing Salmonella species are usually multidrug-resistant and have been recovered from foods of animal origin [18, 19]. The present study evaluated the prevalence of multidrug-resistant extended-spectrum beta-lactamase-producing Salmonella in chilled raw chicken meat sold in markets situated in Nigeria.

${ }^{*}$ Corresponding author. E-mail address: imade.stanley@gmail.com (Odaro Stanley Imade) 


\section{Experimental}

\subsection{Study area}

The study areas included four major open markets in South-Southern Nigeria, namely, Oja-Oba and Effurun main markets situated in Delta State $\left(5.7040^{\circ} \mathrm{N}, 5.9339^{\circ}\right.$ E) and Ondo State $\left(6.9149^{\circ} \mathrm{N}, 5.1478^{\circ} \mathrm{E}\right)$ respectively, as well as Oja-Oba and Oba markets situated in Ekiti State $\left(7.7190^{\circ} \mathrm{N}, 5.3110^{\circ} \mathrm{E}\right)$ and Edo State $\left(6.6342^{\circ} \mathrm{N}\right.$, $\left.5.9304^{\circ} \mathrm{E}\right)$ respectively.

\subsection{Sample collection}

The sampling regime was carried out between October 2017 and September 2020. The samples were collected using simple random sampling methods. The portions of the chilled raw chicken meat used for bacteriological analysis included both the skin and its muscle tissues. Two hundred and forty chicken meat samples were collected from all the markets that were sampled. The samples were placed in sterile stomacher bags and sealed appropriately. All the samples were conveyed to the laboratory after collection in black polyethylene bags placed within ice packs.

\subsection{Reagents}

Buffered peptone water (Becton and Dickinson, USA), Xylose Lysine Deoxycholate (XLD) agar (HiMedia Laboratories, India), Novobiocin (Sigma-Aldrich, Germany), ExoSAP-IT (ThermoFisher Scientific, USA), Salmonella $\mathrm{O}$ and $\mathrm{H}$ antisera (Difco, USA), Antibiotic discs (Abtek Biologicals Ltd., UK),

\subsection{Detection and enumeration of multidrug-resistant extended-spectrum beta-lactamase (ESBL)-producing Salmonella}

Detection and enumeration of Salmonella spp. in the raw chicken meat was performed by the meat rinse centrifugation-plating technique as previously described [20-22]. $25 \mathrm{~g}$ portions of each chicken meat sample were cut into small pieces with sterile forceps/scissors and placed in a sterile bag containing $150 \mathrm{ml}$ sterile $0.1 \%$ buffered peptone water (Becton and Dickinson, USA). The chicken meat was massaged and rotated in the sterile bag for at least 2 minutes to rinse the meat into the peptone water. $25 \mathrm{ml}$ of the rinsate was collected in a sterile bottle and centrifuged at $4470 \mathrm{~g}$ for 20 minutes, followed by the removal of $1 \mathrm{ml}$ sediment that was used to make serial dilutions up to $10^{-6} .10 \mu \mathrm{l}$ of each of the dilutions was spread plated onto sterile duplicate Petri dishes containing Xylose Lysine Deoxycholate (XLD) agar supplemented with novobiocin $(15 \mathrm{mg} / \mathrm{l})$. The inoculated plates were then incubated at $37^{\circ} \mathrm{C}$ for 48 hours. After incubation, colonies on the Petri plates were counted. The colony counts were used to deduce the presumptive Salmonella counts (PSC), expressed as presumptive Salmonella colony-forming units per milliliter of the rinsate.

\subsection{Genus-level identification of the presumptive Salmonella isolates}

Genus-level identification of presumptive Salmonella colonies was performed by previously described phenotypic techniques [23].

\subsection{Species-level identification of the Salmonella isolates}

Species-level identification was performed by polymerase chain reaction (PCR) and sequencing of $16 \mathrm{~S}$ rRNA amplicons [24]. Ultrapure DNA templates were extracted from the identified Salmonella isolates using the Zymo-Spin column (Zymo Research Corporation, Irvine, CA, USA). Universal 16S rRNA bacterial primers (Table 1) were used to detect 16S rRNA gene in the Salmonella isolates and Salmonella enterica subsp. enterica serovar Typhimurium ATCC 14028 was used as a positive control strain for the PCR. The DNA sequencing of PCR amplicons was performed by the dideoxy chain termination method [25]. ExoSAP-IT (ThermoFisher Scientific, Waltham, MA) was used to clean the PCR amplicons. The cleaned amplicons were then subjected to cycle sequencing with the Big Dye Terminator version 3.1 (Applied Biosystems) followed by quality checking and proofreading with Sequencher version 4.10.1 (Gene Codes Corporation, Ann Arbor, MI). Comparison of the experimentally derived nucleotide sequences (query sequences) against the reference sequence database (rRNA_typestrains/prokaryotic_16S_ribosomal_RNA) was performed with BLASTN 2.8.0+ program (National Center for Biotechnology Information [NCBI]) to confirm the species of the Salmonella isolates.

Table 1. Primers used for detection and sequencing of target genes

\begin{tabular}{|c|c|c|c|c|}
\hline Target & Primer & Sequence $\left(5^{\prime}-3^{\prime}\right)$ & Size (bp) & References \\
\hline 16SrRNA & $\begin{array}{l}27 \mathrm{~F} \\
1492 \mathrm{R}\end{array}$ & $\begin{array}{l}\text { AGAGTTTGATCMTGGCTCAG } \\
\text { GGTTACCTTGTTACGACTT }\end{array}$ & 1466 & [24] \\
\hline blasHV $_{\mathrm{SH}}$ & $\begin{array}{l}b l a_{\mathrm{SHV}}-\mathrm{F} \\
\text { bla }_{\mathrm{SHV}}-\mathrm{R}\end{array}$ & $\begin{array}{l}\text { ATGCGTTATATTCHCCTGTG } \\
\text { TGCTTTGTTCCGGGCCAAAC }\end{array}$ & 774 & [30] \\
\hline$b l a_{\operatorname{TEM}}$ & $\begin{array}{l}b l a_{\operatorname{TEM}-F} \\
b l a_{\operatorname{TEM}-\mathrm{R}}\end{array}$ & $\begin{array}{l}\text { ATAAAATTCTTGAAGACGAAA } \\
\text { GACAGTTACCAATGCTTAATC }\end{array}$ & 1080 & [29] \\
\hline blactX-M & $\begin{array}{l}\text { bla } a_{C \mathrm{TX}-\mathrm{M}-\mathrm{F}} \\
\text { blactX-M }-\mathrm{R}\end{array}$ & $\begin{array}{l}\text { CCCATGGTTAAAAAACACTGC } \\
\text { CAGCGCTTTTGCCGTCTAAG }\end{array}$ & 950 & [31] \\
\hline
\end{tabular}

bp: base pair

\subsection{Serological examinations}

Confirmed Salmonella isolates that were identified by the phenotypic tests and 16S rRNA gene sequence analysis were used for the serological examination. The antigenic formula of a pure Salmonella culture was identified by a slide agglutination test that was performed by separately mixing one drop of the different Salmonella $\mathrm{O}$ and $\mathrm{H}$ antisera with a saline emulsion of the pure culture on a slide for 1 minute followed by observing for agglutination using indirect lighting over a dark background. The antigenic formula derived upon completion of the agglutination tests was used to identify the Salmonella serotype by referring to a Kauffmann-White reference scheme [26]. The antigenic formula gave the $\mathrm{O}$ antigens first, followed by the $\mathrm{H}$ antigens, precisely, in the following order: $\mathrm{O}$ antigens - Vi antigens (when present) - $\mathrm{H}$ antigens phase 1 - $\mathrm{H}$ antigens phase 2 (when present), with colons separating the major antigens and commas separating the components of the antigens.

\subsection{Antibiotic susceptibility testing}

Multidrug resistance in the Salmonella isolates was detected by the Kirby Bauer disc diffusion test as previously described by the Clinical and Laboratory 
Standards Institute (CLSI) [27]. Inhibitory zone diameter around each of the Salmonella colonies was interpreted as sensitive, intermediate, or resistant according to interpretive standards set by the CLSI. The reference strain was Staphylococcus aureus ATCC 25923. Ampicillin $(10 \mu \mathrm{g})$, Amoxycillin/Clavulanic acid $(20 \mu \mathrm{g})$, Amikacin $(30 \mu \mathrm{g})$, Ceftazidime $(30 \mu \mathrm{g})$, Cefotaxime $(30 \mu \mathrm{g})$, Ceftriaxone $(30 \mu \mathrm{g})$, Streptomycin $(10 \mu \mathrm{g})$, Tobramycin $(20 \mu \mathrm{g})$, Gentamycin $(10 \mu \mathrm{g})$, Nalidixic acid $(30 \mu \mathrm{g})$, Ofloxacin $(5 \mu \mathrm{g})$, Ciprofloxacin (5 $\mu \mathrm{g})$, Sulfamethoxazole/trimethoprim (25 $\mu \mathrm{g})$, Tetracycline $(30 \mu \mathrm{g})$ and Chloramphenicol $(30 \mu \mathrm{g})$ were the antibiotic discs (Abtek Biologicals Ltd., UK) that were tested.

\subsection{Estimation of multidrug-resistant Salmonella}

The tested Salmonella species were confirmed to be multidrug-resistant if they exhibited resistance to at least three antibiotics from three different antibiotic classes. The prevalence of multidrug-resistant Salmonella $(P)$ in each of the samples examined in this study was deduced as follows:

$P=\frac{\text { Count of Salmonella isolates that were multidrug-resistant }}{\text { Totalcount of Salmonella isolates examined }}$

The count of multidrug-resistant Salmonella (MRS) in each of the samples examined in this study was deduced using Equation 2:

$M R S=P \times$ Presumptive Salmonella count (PSC)

where: $P=$ prevalence of multidrug-resistant Salmonella.

\subsection{Estimation of multiple antibiotic resistance indices}

The multiple antibiotic resistance indices (MAR) of the Salmonella isolates used to estimate the risk of acquiring multidrug-resistant Salmonella from the raw chicken meat samples were determined according to the method previously described by Krumperman [28]. MAR value (Equation 3) of greater than 0.2 is indicative of a highrisk source of acquiring multidrug-resistant Salmonella from the raw chicken meat.

$$
\mathrm{MAR}=\frac{\sum(\mathrm{AR})}{\mathrm{A} \times \mathrm{B}}
$$

where: $\mathrm{MAR}=$ mean multiple antibiotic resistance indices; $\mathrm{AR}=$ antibiotic resistance scores of each Salmonella isolate (AR is defined as the sum of antibiotic classes to which a particular Salmonella isolate exhibited resistance); $\mathrm{A}=$ total number of antibiotic classes tested; B = total count of Salmonella isolates examined.

\subsection{Phenotypic detection of Extended-Spectrum Beta-lactamases (ESBL)}

ESBL phenotype in the multidrug-resistant Salmonella isolates was determined by double-disc synergy test (DDST) and the combination disc test as previously described [27]. Salmonella enterica subsp. enterica serovar Typhimurium ATCC 14028 was used as a positive control strain for the ESBL production test.

\subsection{Characterization of the ESBL genes}

Characterization of the multidrug-resistant Salmonella isolates exhibiting ESBL phenotypes were further analyzed to detect their ESBL gene variants by PCR and DNA sequencing of the ESBL-encoding genes ( bla $_{\mathrm{SHV}}$, $b l a_{\mathrm{TEM}}$, and $\left.b l a_{\mathrm{CTX}-\mathrm{M}}\right)$. The primers employed for ESBL confirmation are shown in Table 1. The PCRs were performed in a MyCycler PCR system (Bio-Rad, Hercules, CA) under conditions described in earlier works [29-31]. The PCR assay was carried out in a 0.2 $\mathrm{ml}$ thin wall tube. Each tube consisted of a $25 \mu 1$ mixture containing $1.5 \mathrm{mM} \mathrm{MgCl}_{2}, 0.2 \mu \mathrm{M}$ of each primer, 200 $\mu \mathrm{M}$ of each of the deoxynucleoside triphosphates (dNTPs), 1.5 U of Taq polymerase (CinnaGen, Tehran, Iran), and $2.0 \mu \mathrm{l}$ of DNA template. The PCR cycling condition for blaCTX-M and blaSHV was maintained as follows: initial denaturation at $94{ }^{\circ} \mathrm{C}$ for 7 minutes; 30 cycles of amplification with denaturation at $94{ }^{\circ} \mathrm{C}$ for 30 seconds; annealing at $57^{\circ} \mathrm{C}$ for 30 seconds; extension at $72{ }^{\circ} \mathrm{C}$ for 30 seconds and a final extension at $72{ }^{\circ} \mathrm{C}$ for 5 minutes. For the blaTEM gene, the PCR cycling condition was the same as those for blaCTX-M and blaSHV except that the annealing temperature for the blaTEM gene was maintained at $53{ }^{\circ} \mathrm{C}$.

The PCR products were subsequently run on a $2 \%$ agarose gel and sequencing performed as previously described. Comparison of the experimentally derived nucleotide sequences (query sequences) against the reference sequence database (non-redundant protein sequences) was performed with BLASTX 2.8.0+ program (NCBI) to identify the specific class A extended-spectrum beta-lactamases expressed by the ESBL genes in the multidrug-resistant Salmonella isolates. All non-redundant GenBank CDS translations + PDB + SwissProt + PIR + PRF excluding environmental samples from WGS projects were searched for protein sequences that were homologous to the translated nucleotide query sequences of each of the multidrug-resistant Salmonella isolates.

\subsection{Characterization of the ESBL expressed by the ESBL genes}

To understand the structure/sequence/function relationships associated with the ESBL enzymes, putative conserved domains in the translated nucleotide query sequences of each of the multidrug-resistant Salmonella isolates were annotated by performing a reverse position-specific BLAST (RPS-BLAST) search with the conserved domain database program version 3.16 (NCBI). The three-dimensional (3D) domains of the ESBL were also annotated with the Cn3D version 4.3 modeling software.

\subsection{Estimation of multidrug-resistant ESBL- producing Salmonella}

The prevalence of multidrug-resistant ESBL-producing Salmonella $(P)$ in each of the samples examined in this study was deduced as follows:

$$
P=\frac{\text { Count of multidrug-resistant Salmonella isolates that produced ESBL }}{\text { Totalcount of Salmonella isolates examined }}
$$

The count (concentration) of multidrug-resistant ESBL-producing Salmonella (MRES) in each of the 
samples examined in this study was deduced using Equation 5:

$$
\text { MRES }=P \times \text { Presumptive Salmonella } \text { count }(P S C)
$$

where: $P=$ prevalence of multidrug-resistant ESBLproducing Salmonella

\subsection{Statistical analysis}

NCSS version 12 data analysis software was employed for descriptive statistical analysis of Salmonella counts and prevalence datasets. Shapiro-Wilk normality test and Fisher $(\mathrm{F})$ one-way ANOVA test for normally distributed datasets were also implemented. The test of the hypothesis was considered statistically significant if the achieved level of significance (p) was less than 0.05 .

\section{Results and discussion}

\subsection{Isolated Salmonella species}

The results of the phenotypic tests for all the Salmonella isolates agreed with the expected standard results for the genus- Salmonella. 16S rRNA gene sequencing test showed that $S$. enterica was the main species that were present in the chicken meat samples. Of the 229 presumptive Salmonella isolates examined, 52 isolates were confirmed as Salmonella species. Ugwu et al. [18], Akbar and Kumar [32], and Pedro et al. [33] detected $S$. enterica in the raw chicken meat samples that they examined. Abdel-Aziz [34] reported a Salmonella incidence of $6.6 \%$ in chicken carcasses collected from Egypt.

\subsection{Salmonella serology}

All the confirmed Salmonella isolates examined belonged to two antigenic formulae. One of the antigenic formulae $(1,4,[5], 12: \mathrm{i}: 1,2$ representing $\mathrm{O}$ antigen factors 1, 4, [5] and 12; the flagella $\mathrm{H}$ antigen I $\left[1^{\text {st }}\right.$ phase $]$ and the flagella $\mathrm{H}$ antigens 1 and $2\left[2^{\text {nd }}\right.$ phase]) indicated the presence of Salmonella enterica subsp. enterica serovar Typhimurium. The other antigenic formula $(1,9,12:[\mathrm{f}], \mathrm{g}, \mathrm{m},[\mathrm{p}]:[1,7]$ representing $\mathrm{O}$ antigen factors 1,9 and 12; the flagella $\mathrm{H}$ antigen factors [f], g, m, [p] [ $1^{\text {st }}$ phase] and the flagella $\mathrm{H}$ antigen $[1,7]$ [ $2^{\text {nd }}$ phase]) indicated the presence of Salmonella enterica subsp. enterica serovar Enteritidis in the raw chicken meat samples. Salmonella enterica subsp. enterica serovar Typhimurium occurred more frequently $(35 / 52 ; 67.31 \%)$ when compared to Salmonella enterica subsp. enterica serovar Enteritidis $(17 / 52 ; 32.69 \%)$. The results of serological assay from this study significantly agreed with the work of AbdelAziz [34] who identified $S$. Typhimurium, $S$. Enteritidis, and $S$. Kentucky in the chicken meat samples that were examined. $S$. enterica subsp. enterica serovar Typhimurium and $S$. enterica subsp. enterica serovar Enteritidis have been variously asserted to be the most frequently isolated serovars that cause foodborne outbreaks in the world [35, 36]. GenBank accession numbers for representative Salmonella serotypes isolated from the raw chicken meat samples were Salmonella enterica subsp. enterica serovar Typhimurium strain OGUAKINNIBOSUN 234 (MW426267), Salmonella enterica subsp. enterica serovar Enteritidis strain OGUAKINNIBOSUN 235 (MW426268), Salmonella enterica subsp. enterica serovar Typhimurium strain OGUAKINNIBOSUN 236 (MW426269), Salmonella enterica subsp. enterica serovar Typhimurium strain OGUAKINNIBOSUN 237 (MW633955), Salmonella enterica subsp. enterica serovar Typhimurium strain OGUAKINNIBOSUN 238 (MW639905) and Salmonella enterica subsp. enterica serovar Enteritidis strain OGUAKINNIBOSUN 239 (MW641980).

\subsection{Antibiotic resistance profile and multiple antibiotic resistance indices estimates}

The antibiotic resistance profile of Salmonella isolates obtained from the chicken meat samples is presented in Table 2. Of the 52 Salmonella isolates tested, 46 Salmonella isolates were found to be multidrugresistant. Multidrug-resistant Salmonella isolates were most prevalent in raw chicken meat samples vended in Edo State and least prevalent in Ekiti State. Overall, the Salmonella isolates were most resistant to ampicillin $(96.15 \%)$ but were more sensitive to gentamycin (40.39\%). Amongst the Salmonella isolates obtained from the chicken meat samples collected from the different sampling locations, MAR ranged from 0.69 to 0.87 . Overall, MAR was estimated at 0.83 . These MAR values in the raw chicken meat samples collected from all the sampling locations exceeded the recommended limit of 0.2 , thus, indicating that raw chicken meat from South-Southern Nigeria was a potential source of multidrug-resistant Salmonella with a probable significant health risk. Antunes et al. [11], Ugwu et al. [18], and Parvin et al. [19] have also detected multidrugresistant Salmonella in chicken meat samples. Thus, poultry products are currently identified as a public health concern. The huge data on the association of multidrug-resistant Salmonella with chicken meat is extremely worrying due to the probable resistance of Salmonella to an array of antibiotics that are clinically relevant [11].

Table 2. Antibiotic resistance pattern of the Salmonella isolates

\begin{tabular}{|c|c|c|c|c|c|c|c|c|c|c|c|c|c|c|c|c|c|c|c|c|}
\hline \multirow[t]{2}{*}{ Sampling locations } & \multirow[t]{2}{*}{ B } & \multicolumn{15}{|c|}{ Prevalence of antibiotic resistance } & \multirow[t]{2}{*}{$\mathbf{M R}$} & \multirow[t]{2}{*}{$\sum(A R)$} & \multirow[t]{2}{*}{$\mathrm{A}$} & \multirow[t]{2}{*}{ MAR } \\
\hline & & $\begin{array}{c}\text { AMC } \\
20 \mu \mathrm{g} \\
(\%)\end{array}$ & $\begin{array}{c}\text { AMP } \\
10 \mu \mathrm{g} \\
(\%)\end{array}$ & $\begin{array}{c}\mathrm{AK} \\
30 \mu \mathrm{g} \\
(\%)\end{array}$ & $\begin{array}{c}\text { CTX } \\
30 \mu \mathrm{g} \\
(\%)\end{array}$ & $\begin{array}{c}\mathrm{CAZ} \\
30 \mathrm{\mu g} \\
(\%)\end{array}$ & $\begin{array}{c}\text { CRO } \\
30 \mu \mathrm{g} \\
(\%)\end{array}$ & $\begin{array}{c}\mathrm{CN} \\
10 \mathrm{\mu g} \\
(\%)\end{array}$ & $\begin{array}{c}\text { TOB } \\
20 \mu \mathrm{g} \\
(\%)\end{array}$ & $\begin{array}{c}\text { STR } \\
10 \mu \mathrm{g} \\
(\%)\end{array}$ & $\begin{array}{l}\text { CIP } \\
5 \mu \mathrm{g} \\
(\%)\end{array}$ & $\begin{array}{c}\text { NAL } \\
30 \mu \mathrm{g} \\
(\%)\end{array}$ & $\begin{array}{c}\text { OFX } \\
5 \mu \mathrm{g} \\
(\%)\end{array}$ & $\begin{array}{c}\text { SXI } \\
25 \mu \mathrm{g} \\
(\%)\end{array}$ & $\begin{array}{c}\text { TET } \\
30 \mu \mathrm{g} \\
(\%)\end{array}$ & $\begin{array}{c}\text { CAM } \\
30 \mu \mathrm{g} \\
(\%)\end{array}$ & & & & \\
\hline Delta State & 14 & 64.29 & 100.00 & 50.00 & 50.00 & 50.00 & 50.00 & 50.00 & 71.43 & 100.00 & 50.00 & 64.29 & 85.71 & 57.14 & 85.71 & 57.14 & 12 & 75 & 7 & 0.77 \\
\hline Ondo State & 9 & 77.78 & 100.00 & 77.78 & 77.78 & 77.78 & 77.78 & 77.78 & 77.78 & 100.00 & 77.78 & 77.78 & 88.89 & 77.78 & 88.89 & 77.78 & 8 & 55 & 7 & 0.87 \\
\hline Edo State & 23 & 82.61 & 95.65 & 73.91 & 52.17 & 82.61 & 65.22 & 30.44 & 82.61 & 100.00 & 56.52 & 82.61 & 91.30 & 82.61 & 91.30 & 82.61 & 21 & 144 & 7 & 0.89 \\
\hline Ekiti State & 6 & 50.00 & 83.33 & 0.00 & 0.00 & 50.00 & 0.00 & 0.00 & 50.00 & 83.33 & 0.00 & 50.00 & 83.33 & 50.00 & 83.33 & 50.00 & 5 & 29 & 7 & 0.69 \\
\hline All sampling locations & 52 & 73.08 & 96.15 & 59.62 & 50.00 & 69.23 & 55.77 & 40.39 & 75.00 & 98.08 & 51.92 & 73.08 & 88.46 & 71.15 & 88.46 & 71.15 & 46 & 303 & 7 & 0.83 \\
\hline
\end{tabular}

B: Counts of Salmonella isolates; AMC: Amoxicillin/Clavulanic acid; AMP: Ampicillin; AK: Amikacin; CTX: Cefotaxime; CAZ: Ceftazidime; CRO: Ceftriaxone; CN: Gentamycin; TOB: Tobramycin; STR: Streptomycin; CIP: Ciprofloxacin; NAL: Nalidixic acid; OFX: Ofloxacin; SXT: Sulfamethoxazole/Trimethoprim; TET: Tetracycline; CAM: Chloramphenicol; MR: Counts of multidrug-resistant Salmonella; AR: Antibiotic 
resistance scores; A: Counts of antibiotic classes; MAR: Mean multiple antibiotic resistance indices. Zone diameter interpretive standards stipulated by the Clinical and Laboratory Standards Institute were used to determine the susceptibility or resistance of the selected antibiotics to the Salmonella species isolated from the raw chicken meat samples.

\subsection{Detected ESBL genes}

The double-disc diffusion synergy and combination tests confirmed 41 isolates as multidrug-resistant ESBLproducing Salmonella species out of the 46 multidrugresistant Salmonella isolates tested. The sequence analysis of the PCR products (Figure 1) with BLASTX software revealed the presence of bla $a_{\mathrm{TEM}}, b_{\text {s }} a_{\mathrm{SHV}}$, and bla $a_{\text {СтХ-м }}$ genes in the Salmonella isolates examined. The bla $a_{\text {CTX-M }}$ genes were found to be the most prevalent genes since they occurred in $92.68 \%$ of the multidrugresistant Salmonella isolates examined, while bla $a_{\mathrm{TEM}}$ were the least prevalent beta-lactamase genes (31.71\%) amongst the multidrug-resistant Salmonella isolates examined. The $b l a_{\mathrm{SHV}}$ genes occurred in $68.29 \%$ of the multidrug-resistant Salmonella isolates examined. Fifty percent of the multidrug-resistant Salmonella isolates co-carried the $b l a_{\text {СтХ-м }}$ and $b l a_{\mathrm{SHV}}$ genes, while $34.15 \%$ of the isolates co-carried the bla $a_{\text {СTХ-м }}$ and bla $a_{\text {TEM }}$ genes. Qiao et al. [13], Saliu et al. [14], Huijbers et al. [16], Valentin et al. [17], Abdel-Azeez [34], and Friese et al. [37] have reported the presence of ESBL in chicken meat. Friese et al. [37] documented that ESBLproducing bacteria relatively occurred more in poultry meat than other types of meat. As was also reported in this study, Huijbers et al. [16] and Valentin et al. [17] indicated that CTX-M-1 appeared to be the most prevalent ESBL in poultry meat. They also reported the presence of SHV and TEM in poultry meat. However, an important controversy is whether poultry only serves as a reservoir of ESBL-producing bacteria or is also connected with human infections [14]. GenBank accession numbers for representative ESBL genes obtained from multidrug-resistant ESBL-producing Salmonella serotypes isolated from the chicken meat samples were $S$. enterica subsp. enterica serovar Typhimurium strain OGUAKINNIBOSUN 237 betalactamase CTX-M-1 gene (MW662674), S. enterica subsp. enterica serovar Typhimurium strain OGUAKINNIBOSUN 236 beta-lactamase CTX-M-61 gene (MW662668), S. enterica subsp. enterica serovar Enteritidis strain OGUAKINNIBOSUN 235 betalactamase CTX-M-1 gene (MW662673), S. enterica subsp. enterica serovar Typhimurium strain OGUAKINNIBOSUN 234 beta-lactamase CTX-M-1 gene (MW662672), S. enterica subsp. enterica serovar Enteritidis strain OGUAKINNIBOSUN 239 betalactamase CTX-M-1 gene (MW662676), S. enterica subsp. enterica serovar Typhimurium strain OGUAKINNIBOSUN 238 beta-lactamase CTX-M-1 gene (MW662675), S. enterica subsp. enterica serovar Typhimurium strain OGUAKINNIBOSUN 237 betalactamase SHV-11 gene (MW662671), S. enterica subsp. enterica serovar Enteritidis strain OGUAKINNIBOSUN 235 beta-lactamase SHV-11 gene (MW662670), S. enterica subsp. enterica serovar Typhimurium strain OGUAKINNIBOSUN 234 betalactamase SHV-11 gene (MW662669), S. enterica subsp. enterica serovar Typhimurium strain OGUAKINNIBOSUN 236 beta-lactamase TEM gene (MW678648) and S. enterica subsp. enterica serovar Enteritidis strain OGUAKINNIBOSUN 239 betalactamase TEM gene (MW678649).

Figure 1. PCR showing beta-lactamase extended-spectrum beta-lactamase gene amplification in some of the multidrug-resistant Salmonella isolates obtained from the raw chicken meat

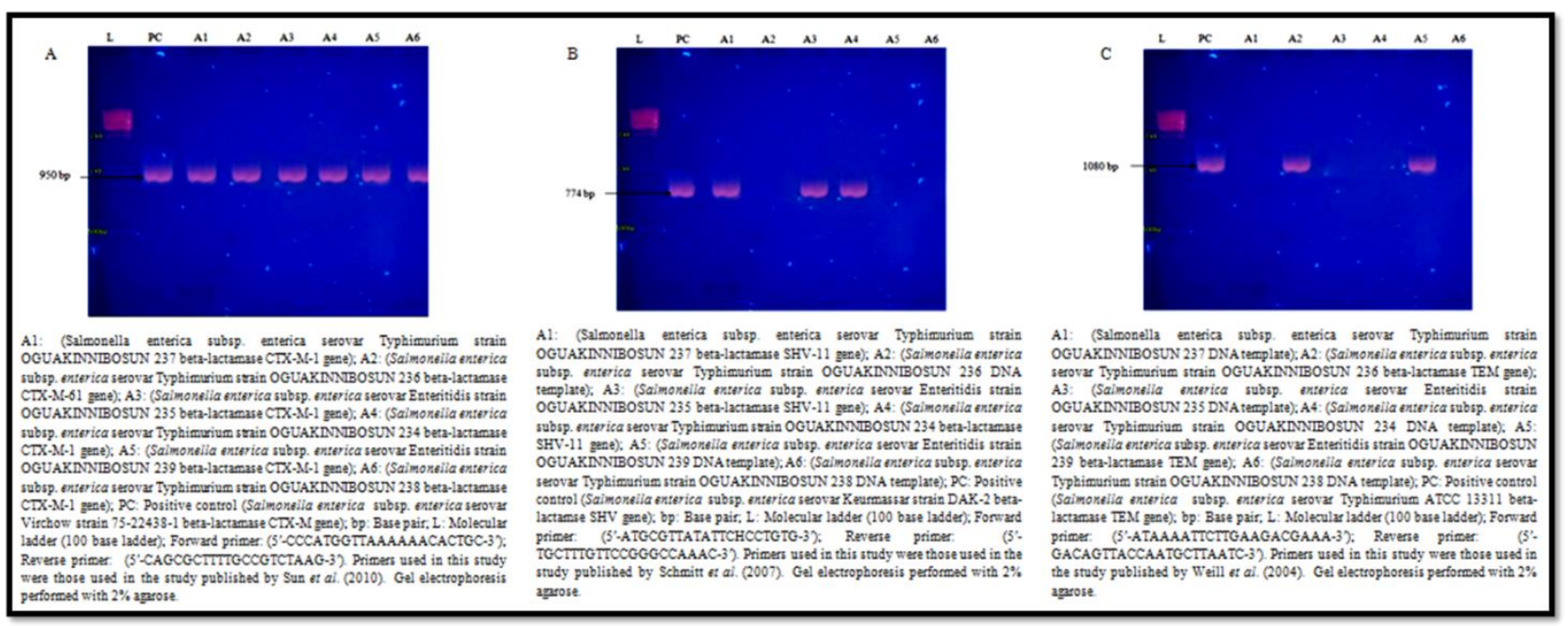

(A): PCR showing beta-lactamase CTX-M gene amplification (B) PCR showing beta-lactamase SHV gene amplification (C) PCR showing betalactamase TEM gene amplification

\subsection{Characterized ESBL}

The conserved domains in the translated ESBL genes characterized by the RPS-BLAST are presented in Figure 2. All the CTX-M, TEM, and SHV beta- lactamases identified by BLASTX were confirmed by the RPS-BLAST as serine-based hydrolases that could cleave to beta-lactam antibiotics and ultimately convert them to substituted beta-amino acids. 
Figure 2. RPS-BLAST performed on ESBL proteins detected in the raw chicken meat

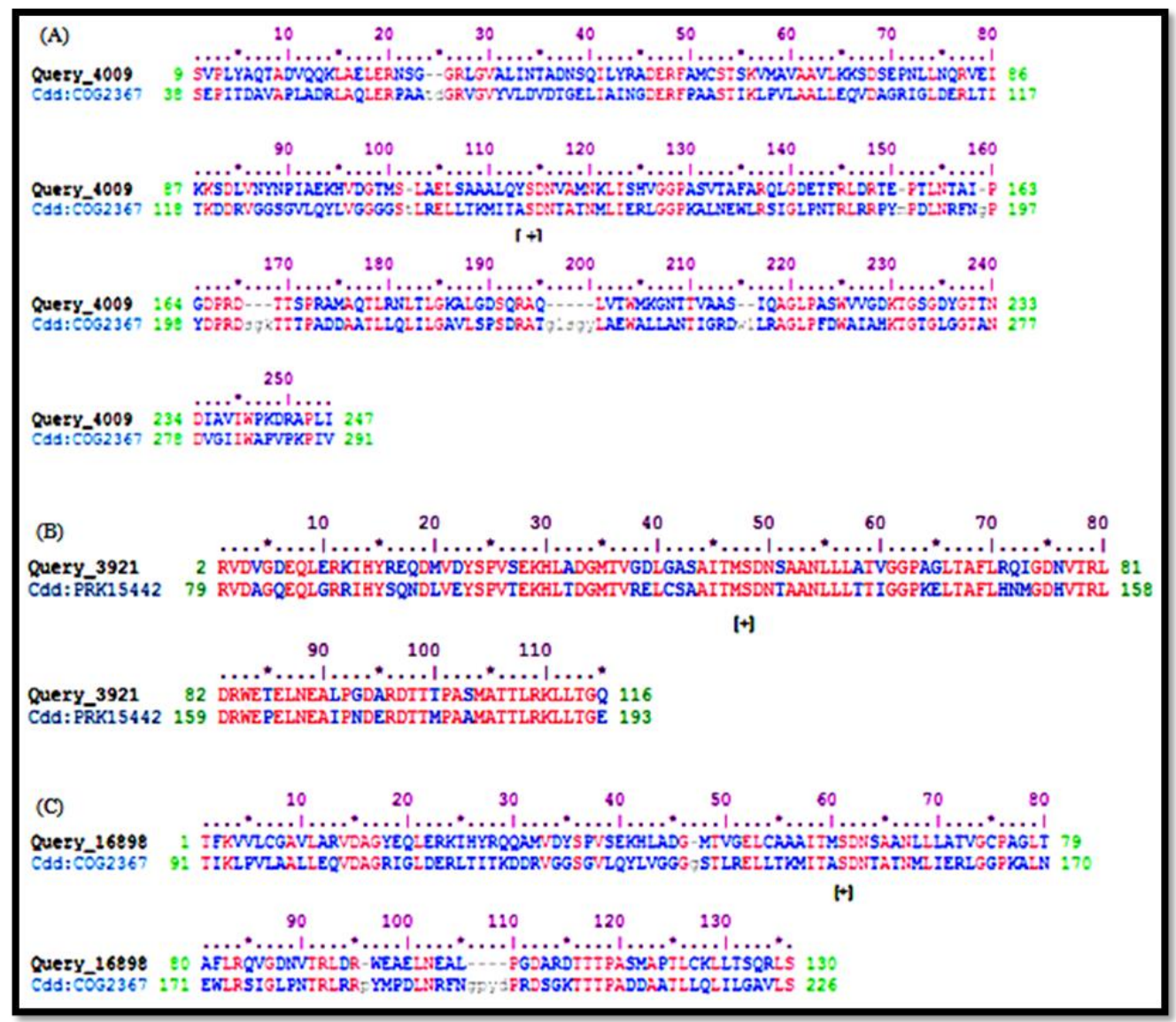

(A) RPS-BLAST pairwise sequence alignment between the reference consensus amino acid sequence of the class A beta-lactamase protein family (Cdd: COG2367) derived from the translated penP gene and those of the query beta-lactamase CTX-M enzyme. Query_4009 is a beta-lactamase CTX-M sequence that was derived from the translated nucleotide sequence of Salmonella Typhimurium strain OGUAKINNIBOSUN 234 (MW662672). (B) RPS-BLAST pairwise sequence alignment between the reference consensus amino acid sequence of the class A beta-lactamase protein family (Cdd: PRK15442) and those of the query beta-lactamase TEM enzyme. Query_3921 is a beta-lactamase TEM sequence that was respectively derived from the translated nucleotide sequence of Salmonella Enteritidis strain OGUAKINNIBOSUN 239 (MW678649). (C) RPS-BLAST pairwise sequence alignments between the reference consensus amino acid sequence of the class A beta-lactamase protein family (Cdd: COG2367) derived from the translated penP gene and those of the query beta-lactamase SHV enzyme. Query_16898 is a beta-lactamase SHV sequence that was derived from the translated nucleotide sequence of Salmonella Typhimurium strain OGUAKINNIBOSUN 237 (MW662671). [+] symbol indicates the specific location of the serine active site within the highly conserved motifs. (- - - ) indicates regions of amino acid sequence deletions in the query beta-lactamase SHV sequences due to mutations in their translated nucleotide sequences. The BLAST was implemented with the conserved domain bioinformatics tool (CD SEARCH/cdd v3.16).

The 3D domain structure of all the class A ESBL found in the raw chicken meat samples is presented in Figure 3. The Cn3D software revealed the two main domains that constitute the $3 \mathrm{D}$ structures of the class $\mathrm{A}$ ESBL proteins, as well as unique ligands such as sodium ion $\left(\mathrm{Na}^{+}\right)$, formic acid (FMT), and glycerol (GOL). GenBank accession numbers for representative CTX-M family class A ESBL obtained from multidrug-resistant ESBL-producing Salmonella serotypes isolated from the chicken meat samples were QTP72438, QTP72442, QTP72443, QTP72444, QTP72445, and QTP72446. GenBank accession numbers for representative SHV family class A ESBL were QTP72439, QTP72440, and QTP72441, while those of the TEM family class A ESBL were QTP72447 and QTP72448.

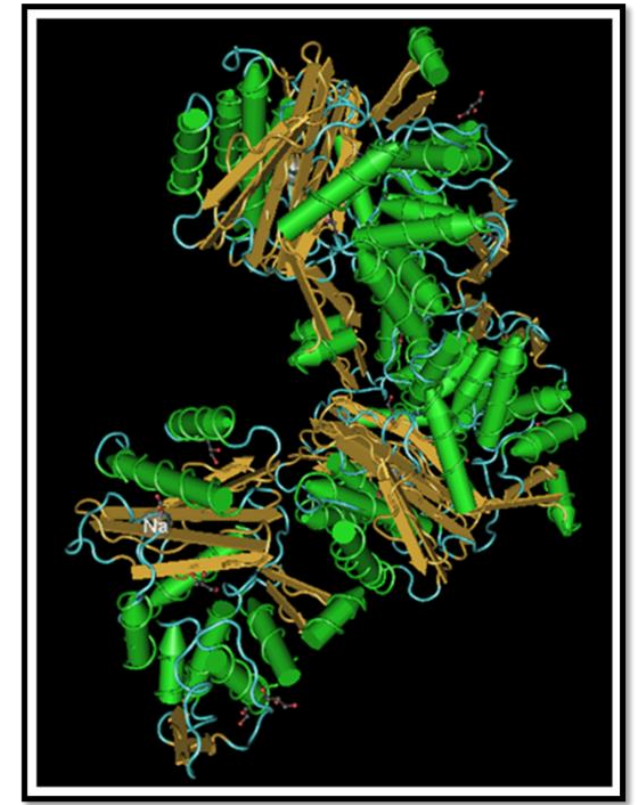

Figure 3. 3D structure of the class A beta-lactamase enzymes produced by the Salmonella enterica strains isolated from the 
raw chicken meat revealing the two domains which constitute the protein. Each 3D domain is shown in the same color. It was implemented in the Cn3D modeling software.

\subsection{Prevalence and counts of Salmonella in the raw chicken meat}

Prevalence and counts of presumptive Salmonella, multidrug-resistant Salmonella and multidrug-resistant ESBL-producing Salmonella present in the raw chicken meat samples are presented in Table 3.

Table 3. Prevalence and counts of Salmonella present in the raw chicken meat

\begin{tabular}{|c|c|c|c|c|c|c|c|c|c|c|c|c|c|}
\hline \multirow[t]{3}{*}{ Sampling locations } & \multirow[t]{3}{*}{$\mathrm{N}$} & \multicolumn{4}{|c|}{ Presumptive salmonella } & \multicolumn{4}{|c|}{ Multidrug-resistant Salmonella } & \multicolumn{4}{|c|}{ Multidrug-resistant ESBL-producing Salmonella } \\
\hline & & \multicolumn{2}{|c|}{ Prevalence } & \multicolumn{2}{|c|}{ Counts (PSC) } & \multicolumn{2}{|c|}{ Prevalence } & \multicolumn{2}{|c|}{ Counts (MRS) } & \multicolumn{2}{|c|}{ Prevalence } & \multicolumn{2}{|c|}{ Counts (IRRES) } \\
\hline & & $\mathrm{F} / \mathrm{X}$ & $P(\%)$ & $\begin{array}{c}\text { Mean }=\text { SD } \\
\left(\log _{10} C F U / m l\right)\end{array}$ & $\begin{array}{c}95 \% \mathrm{CI} \\
\left(\log _{10} \mathrm{CFU} / \mathrm{ml}\right)\end{array}$ & $\mathbf{F X}$ & $\mathrm{P}(\%)$ & $\begin{array}{c}\text { Mean }=\text { SD } \\
\left(\log _{10} \mathrm{CFU} / \mathrm{ml}\right)\end{array}$ & $\begin{array}{c}95 \% \mathrm{CI} \\
\left(\log _{10} \mathrm{CFU} / \mathrm{ml}\right)\end{array}$ & $\mathrm{F} X \mathrm{X}$ & $P(\%)$ & $\begin{array}{c}\text { Mean }=\mathrm{SE} \\
\left(\log _{10} \mathrm{CFU} / \mathrm{ml}\right)\end{array}$ & $\begin{array}{c}95 \% \mathrm{CI} \\
\left(\log _{10} \mathrm{CFU} / \mathrm{ml}\right)\end{array}$ \\
\hline Delta State & 60 & 14,64 & 21.88 & $5.79=5.22$ & $4.47-7.11$ & 1264 & 18.75 & $5.06=5.01$ & $3.79-6.33$ & 10.64 & 15.63 & $4.98=4.35$ & $3.88-6.08$ \\
\hline Ondo State & 60 & $9 / 41$ & 21.95 & $4.48=4.61$ & $3.31-5.65$ & $8 / 41$ & 19.51 & $3.77=3.70$ & $2.83-4.71$ & $7 / 41$ & 17.07 & $3.71=3.49$ & $2.83-4.59$ \\
\hline Edo State & 60 & $23 / 91$ & 25.28 & $6.74=6.78$ & $5.03-8.46$ & $21 / 91$ & 23.08 & $6.10=5.98$ & $4.59-7.61$ & 20,91 & 21.98 & $6.08=5.91$ & $4.59-7.58$ \\
\hline Ekiti State & 60 & $6 / 33$ & 18.18 & $4.74=4.15$ & $3.69-5.79$ & $5 / 33$ & 15.15 & $3.92=3.52$ & $3.03-4.81$ & $4 / 33$ & 12.12 & $3.82=3.32$ & $2.98-4.66$ \\
\hline All sampling locations & 240 & 522229 & 22.71 & $6.19=6.42$ & $5.38-7.00$ & 46.229 & 20.09 & $5.54=5.79$ & $4.81-6.27$ & $41 / 229$ & 17.90 & $5.52=5.77$ & $4.79-6.25$ \\
\hline
\end{tabular}

$\mathrm{N}$ : Counts of the raw chicken meat samples examined. F: Counts of Salmonella that were identified as presumptive Salmonella, multidrug-resistant Salmonella or multidrug-resistant ESBL-producing Salmonella. P: Percentage prevalence of Salmonella in the raw chicken meat. PSC: Presumptive Salmonella counts. MRS: Multidrug-resistant Salmonella counts. MRES: Multidrug-resistant ESBL Salmonella counts. SD: Standard deviation. The counts are presented as mean \pm standard deviation of mean.

Overall, the prevalence of presumptive Salmonella, multidrug-resistant Salmonella, and multidrug-resistant ESBL-producing Salmonella were respectively estimated at $22.71 \%, 20.09 \%$, and $17.90 \%$, while the mean counts were estimated at $6.19 \pm 6.42 \log _{10}$ $\mathrm{CFU} / \mathrm{ml}, 5.54 \pm 5.79 \log _{10} \mathrm{CFU} / \mathrm{ml}$, and $5.52 \pm 5.77$ $\log _{10} \mathrm{CFU} / \mathrm{ml}$ respectively. Shapiro-Wilk test showed that the dataset of counts of presumptive Salmonella was normally-distributed ( $\mathrm{p}=0.79 ; \alpha=0.05)$. The datasets of counts of multidrug-resistant Salmonella and multidrug-resistant ESBL-producing Salmonella were also normally-distributed $(\mathrm{p}=0.61$ and 0.54 , respectively). Based on the results of the normality test, parametric Fisher one-way analysis of variance (ANOVA) tests within each of the datasets indicated no significant difference $(\mathrm{p}=0.72,0.55$, and 0.52 for presumptive Salmonella, multidrug-resistant Salmonella, and multidrug-resistant ESBL-producing Salmonella respectively). The ANOVA test between the Salmonella datasets also indicated no significant difference $(p=0.54)$. The counts reported in this study were higher than those reported by Briehta-Harhay et al. [38] who worked with chicken meat from the United States. However, Vaidya et al. [39], Lindblad et al. [40], and Maharjan et al. [41] in their various studies did not detect Salmonella in the chicken meat samples that were examined. Overall, the prevalence of the chilled raw chicken meat contaminated with Salmonella was estimated at $0.17(40 / 240)$. This value of prevalence exceeded the limits $(\leq 0.1)$ set by the Meat Industry Guide, United Kingdom [42]. Improper handling by workers and poor hygienic conditions of the meat processing plants, as well as the meat retailing environment, are the probable sources of contamination of chicken meat sold in the open markets [41]. Improper slaughtering and manual evisceration process of the raw chicken meat intestinal contents could also be an important source of contamination of the meat with Salmonella species.

\section{Conclusions}

This study revealed that multidrug-resistant ESBLproducing Salmonella was widespread in raw chicken meat vended in the Nigerian markets. This might be linked to the extensive use of antibiotics in poultry farms. The probable transmission of ESBL-producing Salmonella strains from the contaminated chicken meat to humans is a potential public health threat. Hence there is a need for the relevant regulatory agencies and other policymakers to enforce food safety.

\section{Conflict of interest}

No conflict of interest declared.

\section{References}

[1]. K. Hoelzer, A I. Moreno-Switt, M. Wiedmann, Animal contact as a source of human nontyphoidal salmonellosis, Veterinary Resources 42 (2011) 34.

[2]. A.S. Khan, K. Georges, S. Rahaman, W. Abdela, A.A. Adesiyun, Prevalence and serotypes of Salmonella spp. on chickens sold at retail outlets in Trinidad, PLoS ONE 13 (2018) e0202108.

[3]. E.K. Barbour, D.B. Ayyash, W. Alturkistni, A. Alyahiby, S. Yaghmoor, A. Iyer, Impact of sporadic reporting of poultry Salmonella serovars from selected developing countries, Journal of Infection in Developing Countries 9 (2015) 1-7.

[4]. Y.T. Ta, T.T. Nguyen, P.B. To, X. Pham da, H.T. Le, W.Q. Alali, Prevalence of Salmonella on chicken carcasses from retail markets in Vietnam, Journal of Food Protection 75 (2012) 1851- 1854.

[5]. S.R. Badhe, M.N. Fairoze, S. Sudarshan, Prevalence of food-borne pathogens in market samples of chicken meat in Bangalore, India, Indian Journal of Animal Resources 47 (2013) 262 $-264$.

[6]. B. Hardy, N. Crilly, S. Pendleton, A. Andino, A. Wallis, N. Zhang, Impact of rearing conditions on the microbiological quality of raw retail poultry meat, Journal of Food Sciences 78 (2013) M1232 - M1235.

[7]. C. Jarquin, D. Alvarez, O. Morales, A.J. Morales, B. Lopez, P. Donado, M.F. Valencia, A. Arevalo, F. Munoz, I. Walls, M.P. Doyle, W.Q. Alali, Salmonella on raw poultry in retail markets in 
Guatemala: levels, antibiotic susceptibility, and serovar distribution, Journal of Food Protection 78 (2015) 1642 - 1650.

[8]. R. Bada-Alambedji, A. Fofana, M. Seydi, A.J. Akakpo, Antimicrobial resistance of Salmonella isolated from poultry carcasses in Dakar (Senegal), Brazilian Journal of Microbiology 37 (2006) 510 515.

[9]. P. Padungtod, J.B. Kaneene, Salmonella in food animals and humans in northern Thailand, International Journal of Food Microbiology 108 (2006) 346 - 354.

[10]. E. Alvarez-Fernandez, C. Alonso-Calleja, C. Garcia-Fernandez, R. Capita, Prevalence and antimicrobial resistance of Salmonella serotypes isolated from poultry in Spain: comparison between 1993 and 2006, International Journal of Food Microbiology 153 (2012) $281-287$.

[11]. P. Antunes, J. Mourão, J. Campos, L. Peixe, Salmonellosis: the role of poultry meat, Clinical Microbiology and Infection 22 (2016) 110 - 121.

[12]. Y. Jin, J.M. Ling, CTX-M-producing Salmonella spp. in Hong Kong: An emerging problem, Journal of Medical Microbiology 55 (2006) 1245 - 1250.

[13]. J. Qiao, Q. Zhang, W.Q. Alali, J. Wang, L. Meng, Y. Xiao, Characterization of extended-spectrum beta-lactamases (ESBLs)-producing Salmonella in retail raw chicken carcasses, International Journal of Food Microbiology 248 (2017) $72-81$.

[14]. E. Saliu, W. Vahjen, J. Zentek,Types and prevalence of extended-spectrum beta-lactamase producing Enterobacteriaceae in poultry, Animal Health Research Reviews 18 (2017) 46 - 57.

[15]. C. Ghazaei, Phenotypic and molecular detection of $\beta$-lactamase genes bla $a_{\mathrm{TEM}}, b a_{\mathrm{CTX}}$ and bla $a_{\mathrm{SHV}}$ produced by Salmonella spp. isolated from poultry meat, Gene Cell Tissue 5 (2018) e84367.

[16]. P.M. Huijbers, E.A. Graat, A.P. Haenen, M.G. Van Santen, A. Van Essen-Zandbergen, D.J. Mevius, E. Van Duijkeren, A.H. Van Hoek, Extendedspectrum and AmpC betalactamase-producing Escherichia coli in broilers and people living and/or working on broiler farms: prevalence, risk factors and molecular characteristics, Journal of Antimicrobial Chemotherapy 69 (2014) 2669 2675.

[17]. L. Valentin, H. Sharp, K. Hille, U. Seibt, J. Fischer, Y. Pfeifer, G.B. Michael, S. Nickel, J. Schmiedel, L. Falgenhauer, A. Friese, Subgrouping of ESBLproducing Escherichia coli from animal and human sources: an approach to quantify the distribution of ESBL types between different reservoirs, International Journal of Food Microbiology 304 (2014) 805 - 816.

[18]. M.C. Ugwu, C. Omanukwue, C. Chimezie, U. Okezie, C.P. Ejikeugwu, E. Nnnabuife-Iloh, C.O Esimone, Poultry farm and poultry products as sources of multiple antimicrobial-resistant Salmonella and S. aureus, Journal of Tropical Diseases 7 (2019) 1000308.

[19]. S. Parvin, M. Hasan, Y. Ali, E. Haque, Prevalence and multidrug-resistance pattern of Salmonella carrying extended-spectrum $\beta$-lactamase in frozen chicken meat in Bangladesh, Journal of Food Protection 83 (2020) 2107 - 2121.

[20]. J.E. Line, N.J. Stern, C.P. Lattuada, S.T. Benson, Comparison of methods for recovery and enumeration of Campylobacter from freshly processed broilers, Journal of Food Protection 64 (2001) $982-986$.

[21]. S. Rodrigo, A. Adesiyun, Z. Asgarali, W. Swanston, Occurrence of selected foodborne pathogens on poultry and poultry giblets from small retail processing operations in Trinidad, Journal of Food Protection 69 (2006) 1096 - 1105.

[22]. N.A. Cox, R.J. Buhr, D.P. Smith, J.A. Cason, L.L. Rigsby, D.V. Bourassa, Sampling naturally contaminated broiler carcasses for Salmonella by three different methods, Journal of Food Protection (2014) 77493 - 495.

[23]. N.R. Krieg, J.C. Holt, Bergey's Manual of Systematic Bacteriology, 1st ed., Vol. 1, United States, Williams and Wilkins, Baltimore (1984).

[24]. D.J. Lane, 16S/23S rRNA sequencing. In nucleic acid techniques in bacterial systematic, Eds. E. Stackebrandtand M. Goodfellow, New York, John Wiley and Sons (1991).

[25]. F. Sanger, S. Nicklen, A.R. Coulson, DNA sequencing with chain-terminating inhibitors, Proceedings of the National Academy of Science USA 74 (1977) 5463 - 5467.

[26]. G. Kauffmann, Kauffmann white scheme, Journal of Acta Pathologica Microbiologica 61 (1974) 385.

[27]. Clinical and Laboratory Standards Institute (CLSI), Performance Standards for Antimicrobial Susceptibility Testing, Twenty-Fourth Informational Supplement, CLSI document M100S24. Wayne, PA: CLSI (2014).

[28]. P.I. Krumperman, Multiple antibiotic resistance indexing of Escherichia coli to identify high-risk sources of fecal contamination of foods, Applied and Environmental Microbiology 46 (1983) 165 170.

[29]. F.X. Weill, M. Demartin, L. Fabre, P.A. Grimont, Extended-spectrum-beta-lactamase (TEM-52)producing strains of Salmonella enterica of various serotypes isolated in France, Journal of Clinical Microbiology 42 (2004) 3359 - 3362.

[30]. J. Schmitt, E. Jacobs, H. Schmidt, Molecular characterization of extended-spectrum betalactamases in Enterobacteriaceae from patients of two hospitals in Saxony, Germany, Journal of Medical Microbiology 56 (2007) $241-249$.

[31]. Y. Sun, Z. Zeng, S. Chen, J. Ma, L. He, Y. Liu, High prevalence of bla (CTX-M) extendedspectrum beta-lactamase genes in Escherichia coli isolates from pets and emergence of CTX-M-64 in China, Clinical Microbiology and Infection 16 (2010) 1475 - 1481.

[32]. A. Akbar, A. Kumar, Prevalence and antibiogram study of Salmonella and Staphylococcus aureus in poultry meat, Asia Pacific Journal of Tropical Biomedicine 3 (2013) 163 - 168.

[33]. H. Pedro, S.A. Waldemir, D.F. Beatriz, L.A. Virginia, L.A. Dayse, D.P. Dalia, R.D. Elmiro, H.C. Maria, Prevalence and fluoroquinolones 
resistance of Campylobacter and Salmonella isolates from poultry carcasses in Rio de Janeiro, Brazil, Food Control 61 (2016) 243 - 247.

[34]. N.M. Abdel-Aziz, Detection of Salmonella species in chicken carcasses using genus specific primer belong to invA gene in Sohag city, Egypt, Veterinary World 9 (2016) 1125 - 1128.

[35]. H. Herikstad, Y. Motarjemi, R.V. Tauxe, Salmonella surveillance: A global survey of public health serotyping, Epidemiology and Infection 129 (2002) $1-8$.

[36]. W. Ibrahim, W. Abd El-Ghany, S. Nasef, M. Hatem, A comparative study on the use of real time polymerase chain reaction (RT-PCR) and standard isolation techniques for the detection of Salmonella in broiler chicks, International Journal of Veterinary Sciences and Medicine 2 (2014) 67 71.

[37]. A. Friese, J. Schulz, H. Laube, C. Von Salviati, J. Hartung, U. Roesler, Faecal occurrence and emissions of livestock-associated methicillinresistant Staphylococcus aureus (laMRSA) and ESbl/ AmpC-producing E. coli from animal farms in Germany, Berliner und Munchener Tierarztliche Wochenschrift 126 (2013) $175-180$.

[38]. D.M. Briehta-Harhay, T.M. Arthur, M. Koohmaraie. Enumeration of Salmonella from poultry carcass rinses via direct plating methods, Letters in Applied Microbiology 46 (2008) 186 191.

[39]. V.M. Vaidya, A.M. Paturkar, V.S. Waskar, R.J. Zende, D.B. Rawool. Detection of indicator organisms on poultry carcass sites in an organized slaughterhouse, Journal of Muscle and Foods 16 (2005) 289 - 297.

[40]. M. Lindblad, H. Lindmark, S. Thisted Lambertz, R. Lindqvist. Microbiological baseline study of broiler chickens at Swedish slaughterhouses, Journal of Food Protection 69 (2006) 2875 - 2882.

[41]. S. Maharjan, V.S. Chhetri, S.P. Sherchan, O.P. Panta, T.B. Karki, Microbial quality of poultry meat in an ISO 22000:2005 certified poultry processing plant of Kathmandu valley, International Journal of Food Contamination 6 (2019) 8.

[42]. Meat Industry Guide, Microbiological criteria, United Kingdom (2017).

Received: 07.04.2021

Received in revised form: 03.06.2021

Accepted: 04.06.2021 